\title{
SOME INDIAN ORIGINS IN THE LIGHT OF ASTRONOMICAL EVIDENCE
}

\begin{abstract}
$\triangle$ MONG recent communications to the Royal Asiatic Society of Bengal, several dealing with details of a technical character in palæographical and historical studies bear upon points of interest and importance in the archæological investigation of the origin and development of Indian civilization*.

In a discussion by $\mathrm{S}$. N. Chakravarti of the development of the Bengali alphabet from the fifth century A.D. to the end of Mohammedan rule, in which the argument depends upon a detailed examination of variations in form, the Bengali alphabet is derived from a proto-Bengali of the tenth century, which in turn it is suggested can be traced back to certain ancient prototypes in the pictographic script of the Indus Valley civilization. It is also suggested that the Indian system of notation, for which affinity with Egyptian demotic has been indicated, is in reality indigenous in origin, probably to be traced back to the seals of the Indus Valley.
\end{abstract}

Conclusions of a more surprising character, based on astronomical evidence, have been formulated by P. C. Sengupta in a series of papers discussing chronological and other problems in early Indian history. The first of these deals with the date of the Bhärata battle, the great conflict which forms the central incident of that great monument of early Indian literature, the Mahabharata. The date for this battle, as usually accounted, is indicated by three lines of traditional evidence at 3102-3101 B.c. The author, on an examination of one of these traditions, the evidence of the Yudhişthira era, has shown that the astronomical references justify the inference that the great battle took place in 2449 B.C. He now turns to examine the remaining two traditions, the Äryabhata and the Purānic traditions.

The calculation depends upon the dating of the Kaliyuga, which the Mahabharata states had just begun and to which the date February 3102 B.c. is assigned. It cannot, however, be reconciled with the astronomical Kaliyuga, and is shown to be based upon an astronomical calculation in which conditions are correct only for A.D. 499, when the Hindu scientific Siddhantas came into being. It depends upon an incorrect assumption of the position of the solstices of Pandava times and an incorrect annual rate of the precession of the equinoxes. A corrected back calculation from conditions in the heavens corresponding to those recorded in the Mahabharata, that is, conditions in the period February 1924-35, gives a date January 10, 2454 B.C. as the beginning of this Kaliyuga era, and 2449 B.c. as the year of the battle.

This leads to further inquiry as to observation of the solstices in successive ages. This was determined by the phases of the moon in the month of Mãgha, a lunar month of which the beginning at the present time may be from January 15 to February 11 . In the calendar of the Vedic Hindus, this month started the five-year cycle which began "when the sun, the moon and the Dhanişthãs (Delphinis) cross the heavens together; it is the beginning of the Yuga, of the month of Māgha or Tapas, of the light half

* See J. R. Asiat. Soc. Bengal, Letters, 4, 3 (1938) ; issued September 1939 . and of the sun's northerly course". From the astronomical conjunctions to which reference is made in the Mahabharata, it would appear that this reckoning was started (traditionally by Brahma) at about 3050 B.C.

There are three peculiarities of this month : (1) it began with a new moon near Delphinis ; (2) the full moon was near Regulus; (3) the last quarter was conjoined with Antares. Such a month did not come every year, but it was the standard month of Māgha. In our own times it occurred in 1924 during February 5-March 5, a year which for the purpose of this investigation is taken as the gauge year.

References in the Brahmanic and other works directly state or indicate the winter solstice of successive Vedic periods. From these astronomical references fixing the position of the moon in relation to the winter solstice and the beginning of the month Māgha, a matter of ritual importance in connexion with the year-long and other sacrifices, it has been possible to fix by calculation back from the corresponding conditions in recent years a series of dates beginning with 3550 B.c., the earliest date of the age of the Brahmanas, and covering a period of 1,450 years with a possible error of 400 years. It was thus during this period that the Brahmanic literature developed.

Next is considered Madhu-Vidyā, or the "science of Spring" which as here interpreted is really the knowledge of the celestial signal for the coming of spring, addressed to the Aśvins, who are identified with $\alpha$ and $\beta$ Arietis, the prominent stars in the Aśvini cluster. The three stars, $\alpha, \beta$ and $\gamma$ Arietis, form a constellation which is likened to the head of a horse. The Aśvins are spoken of in several passages of the Rig-Veda as riding in the heavens in their triangular, three-wheeled, and spring-bearing chariot.

From certain references it would seem that when the car of the Aśvins first becomes visible at dawn, spring began at some place in the latitude of Kurukşetra in the Punjab. The jealously guarded Madhu-Vidyā or "science of Spring" was thus nothing but knowledge of the celestial signal of the advent of spring - the heliacal rising of $\alpha, \beta$ and $\gamma$ Arietis.

By astronomical calculation it can be shown that this event at the latitude mentioned took place at, say, 4000 B.c. Hence it is beyond question that the Vedic Hindus could find accurately the beginnings of winter, spring and all seasons of the year.

The earliest epigraphic evidence of Vedic chronology from cuneiform inscriptions referring to Indra and other gods of the horse-riding Kharri or Mitanni dates from about 1400 B.C. In the absence of further epigraphic evidence, it is pointed out, this definite finding of the astronomical evidence derived from the literature as to the antiquity and chronology of the Vedas must be allowed to stand. It establishes, it is maintained, that the civilization of the Vedic Hindus was earlier than that of the Indus Valley as evidenced by the remains at Mohenjo-daro.

Finally, in "When Indra became Maghavan", Mr. Sengupta turns to the relation of the Vedic god Indra, the "shedder of rain" and "the wielder of 
the thunderbolt" to the summer solstice. The references to this god in the Rig.Veda, when divested of all allegory, suggest that he is the god of the summer solstice, while the clouds as represented by a demon are unwilling to yield up their watery store until assailed by the thunderbolt hurled by the god.

The monsoons which bring the rains usually burst about June 22 and there is usually a drought which lasts for about a month before the monsoon comes. The demon Susna (drought) is killed by Indra. The fight with Vrtra or Ahi, the cloud demon, is thus an annual affair which takes place when the sun enters the summer solstice, Indra withdrawing his raingiving (or annual) bow with the coming of autumn.

When did Indra become the slayer of Vrtra? The answer given by the Rig-Veda is when Indra by the rising of Maghas became Maghavan. Maghas to us must be the constellation Maghās consisting of $\alpha, \eta, \gamma, \zeta, \mu$ and $\varsigma$ Leonis, at the heliacal rising of which the sun reached the summer solstice at the latitude of Kuruksetra (lat. $30^{\circ} \mathrm{N}$.). This it is shown must have happened in 4170 B.C.

\section{APPLICATIONS OF PHOTOGRAPHY TO ENGINEERING}

TN a paper delivered to the Junior Institution of Engineers on November 4 and published in the journal of the Institution for December, Mr. A. H. Styring gives an account of several practical applications of photography to engineering. He lays special stress on infra-red photography, photography by polarized light, X-ray photography and high-speed photography.

Infra-red sensitive materials have proved of the greatest value in spectroscopy and astronomy. Photographs of the solar spectrum have revealed lines as far as 13,500 A. wave-length. Distance appears hazy on non-colour sensitive materials because the suspended particles of water vapour in the atmosphere, which are transparent and therefore affect vision only slightly, act as a thick medium for deep violet and ultra-violet waves, scattering them, and producing an effect similar to that which would be seen if we were to try to look through a sheet of finely ground glass.

When photographing at great distances, the best results are obtained with infra-red sensitive materials and filters. Infra-red waves are less easily scattered by water and dust particles in the intervening atmosphere than are the shorter rays in the normal visibility range. The power of haze penetration is important and has an engineering application. Research is in progress for the adaptation of infra. red sensitive materials for navigational purposes. Good work has been done up to six miles, and distances up to twenty miles have been claimed. Special infra-red cameras have been fitted to transAtlantic liners in which infra-red film is exposed at 20 -second intervals, each picture being developed and fixed rapidly for viewing in roughly one minute. In the same way application has also been made for military purposes, permitting vision of objects invisible to the eye. Other applications depend mainly on the fact that many dyes and pigments, which absorb strongly in the visible region, either transmit or reflect freely in the near infra-red region. In consequence it is possible to reveal by infra-red photography many structures invisible to the eye, and to differentiate between materials which to the eye appear similar. This has a useful application in photomicrography. Another promising field lies in the direction of research in the realm of elevated temperatures. Heat rays are recorded by infra-red materials.

Polarized light photography is based on the fact that light reflected from a non-metallic surface at an angle of $32-37^{\circ}$ is strongly polarized. At other angles except $90^{\circ}$ it is to variable extents. For this reason the reflection from natural things, separately and combined, has much of the light polarized. The unaided eye fails to detect this, but many objects viewed by a polarizing screen assume a new and strange beauty. The use of polarized light in photography is made possible by the way in which all natural substances reflect polarized light. When a ray of light falls on a sheet of paper, for example, the light that is reflected is composed of two parts, which are called 'specular' and 'diffused' components. The specular component produces 'gloss' and enables us to see more or less distinctly an image of the source of light. If we look at our object through a polarizing screen, we find that we can orient the screen so that practically all the specular reflection is stopped and we see the object by diffusely reflected light. Polarizing screens have recently been made from a quinineiodine compound called 'Herapathite', a thin layer of the substance being cemented between two sheets of plane glass. The use of such a screen permits photographs to be taken obliquely through water or glass.

The principal application of X-rays to industry is the examination of articles during manufacture. Increased penetration is constantly being achieved and the definition of radiographs has been greatly improved. It does not necessitate expensive castings or forgings being either sawn asunder or otherwise destroyed or mutilated. With a little experience, defects such as gas cavities, sand and slag inclusions, metal segregation, etc., can be easily detected. The atomic weight of the substance examined has a marked effect on the depth of penetration of the rays. Apart from this fact, penetration depends on the voltage applied to the tube. For example, 40,000 volts will penetrate $4 \mathrm{in}$. of aluminium, but it requires 250,000 volts to penetrate 4 in. of steel. The gamma radiations of radioactive substances have latterly been employed for the same purposes as $\mathrm{X}$-rays. Owing to their shorter wave-length the gamma rays have a much greater penetrative power.

The author points out that with high-speed photography, the ordinary type of motion camera which has an intermittent film motion and shutter can only be speeded up to ten times its normal speed before rupture takes place. Cameras operating at higher speeds have continuously moving films. In the mechanism of the high-speed camera perfected by the Western Electric Co. and Kodak Ltd. there is incorporated a clock, and this records the exact time when each event in a cycle takes place. 